\title{
Emphasis teaching based on texts in mechanical engineering
}

\author{
Olga Nikolenko ${ }^{1}$, Larisa Babakova ${ }^{1}$, and Boris Morenko ${ }^{1 *}$ \\ ${ }^{1}$ Don State Technical University, 1, Gagarin Sq., 344003, Rostov-on-Don, Russia
}

\begin{abstract}
The article describes features of the Russian emphatic models related to scientific style of speech and it is proved that they are able to develop several topics in the microtext, empower a phrase and convey its pragmatic content, form a certain emotional mood, set a communicative attitude to comprehend the utterance in a new perspective, focus recipient's attention on the emphatic segment, important in a particular situation for the perception of this or that information. The analysis allows us to conclude that emphatic models in the scientific style are communicatively dissected sentences, due to text links and having an existential meaning that creates an evaluative nomination. This emphase property makes it necessary to study it in a foreign audience in classes on the scientific style of speech and to master the skills of its use by foreign students. The correct perception of intonation or accentuation of a phrase segment (emphase) determines the level of development of foreign students' monological speech skills which are necessary due to their communicative needs not only in the sociocultural, but also in the educational and professional spheres. Complex syntagme scientific phrases cause a particular difficulty in perception: their understanding depends on accentuation of separate syntaxemes.
\end{abstract}

\section{Introduction}

The development of new and improvement of existing methods of teaching Russian as a foreign language in the context of the intensification and computerization of learning processes involves finding new ways and technologies for the implementation of the educational process. At the elementary stage of teaching Russian as a foreign language number of problems arises, one of which is the mastering the intonation system: intonation models are distorted due to the influence of the native language, individual speech characteristics of the teacher, personal perception of the learner, etc. This leads to the fact that, on the one hand, foreigners may perceive inaccurately the semantic meanings of a Russian phrase, and on the other hand, an erroneous perception of intonation can give the statement such shades of meaning that the speaker did not lay. In this regard, it becomes especially important not only to highlight the basic models in the intonation system, but to study their variant forms.

The most complex constructions in terms of intonation design and perception of semantic relations are multi-syntagma ones, in which the meaning of the whole significantly depends

\footnotetext{
*Corresponding author: bmorenko@mail.ru
} 
on the intonation models used in in separate syntagmas. Convenient material for studying these relations are syntaxemes related to scientific style of speech. Analyzing lexicogrammatical nature of units belonoing to this specific field of knowledge, one can easily notice their focus on pragmatic content, which we understand as a suggestive statement, constructed with the aim of convincing the recipient to accept the author's viewpoint. The lexical content of the phrase is not so much the specific means of such influence, it is its emphatic intonation when presented to the recipient.

The degree of knowledge of the indicated problem in the linguistic science is comparatively deep. Its description can be found in the works by [1-4], etc., however the application of its conclusions in the Russian as a foreign language methods is superficially. In this regard, the purpose of this article is to describe the ways of transmitting emphase in a technical text and to suggest a technique for their implementation in teaching a scientific style of speech to a foreign audience, which determines the feasibility of considering emphatic models in the indicated way, which is justified by the fact that emphase, due to its special accent and intonation abilities, acts as a helper code to extract an information segment from a speech stream and strengthening suggestion.

\section{Materials and methods}

As a linguistic material for the proposed study, highly specialized technical texts were used (mainly lectures on mechanical engineering), subjected to the methods of linguistic observation and description (when determining the status of emphatic patterns), comparative and contextual analysis (when identifying their functional features), continuous sampling method and statistical calculation (to present a quantitative characteristic of the indicated syntaxemes).

\section{Results}

The modern science of language is characterized by an increasing interest in sounding human speech and the analysis of his speech activity, as one of the foundations of the modern language system. Researchers' attention, in particular, focused on the study of emphase. Emphatic models serve a number of systems in the language, the most important of which is intonation. The tasks of identifying emphatic intonation units and their classification become relevant when considering them from the point of view of teaching Russian as a foreign language.

If we take into account that intonation is an independent level of the language structure performing the function of organizing and dividing the speech stream, then the purpose of emphatic intonation can be seen in its pragmatic property: to orient the addressee of the utterance to the meaningful subtext setting given by the addressee. For example, in paper [5] there is a phrase: "The machining process is part of the manufacturing process containing actions to change the size, shape and properties of the workpiece and their subsequent control". This phrase can be pronounced in two, three or more intonation variants, depending on which of the homogeneous is the priority in the information aspect. Visually, by highlighting the word "subsequent" can also be provided with information about the need for control and the time of its implementation. This suggests that the difference in the sequence of pitches implies a changed attitude of the speaker to the semantic filling of the phrase. and, therefore, forces the listener to take into account the author's subjective attitude to the entire utterance.

In this case, intonational accentuation performs four functions excretory, sense-forming, sense-distinguishing and suggestive (the functions of intonation accent are shown in in table 
1) [6]. A phrase that is said with a different intonation can take on new meaning: "Single and small-scale production is characterized by the release of products in small, rarely or not at all recurring quantities with a wide range of manufactured products" [5].

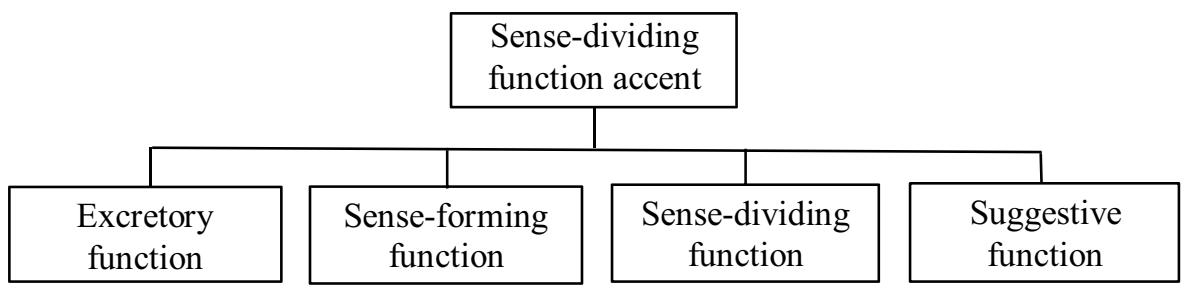

Fig. 1. Functions of intonation accent.

With visual perception of the given example, the information center (remy) is its second part, because it expands and clarifies the information of the first part. If we consider other intonation options that are possible within this syntaxeme, and emphatically highlight, for example, "single and small-scale production", in this case, the language model will acquire a different character with a connotation of comparison (single / small-scale / large-scale).

In emphatic models of a scientific nature in the flow of spoken language, the relationship between the semantics of a word and its accentuation is clearly observed. The greatest emphatic capabilities are possessed by:

1. Excretory-restrictive particles: "Machine adjustments are made by / only / by qualified servicemen [5].

2. Introductory words: "The final dimensions of the workpiece are set taking into account the general allowances and tolerances for the manufacture of the workpiece, on which the necessary parameters are provided, / for example /, radius transitions, molding slopes, etc." [5].

3. Comparative structures: "Symmetrical allowances are assigned for processing the outer and inner surfaces of bodies of revolution, asymmetric ones for processing the surfaces of prismatic parts" [5].

4. Lexemes with a high degree of manifestation of the feature: "The graphic method for constructing the total allowance gives / the most / accurate idea of its components" [5].

5. Syntaxemes that reveal the goals or consequences of the definition: "The unit processing time in all operations is coordinated with the cycle of the production line, / therefore the processed workpieces move from one workstation to another in a continuous flow";

6. Parceled constructions: "The allowance should be minimal. / but sufficient to obtain a part of a given size and quality" [5].

7. Inversion models: "The metal layer required for all technological operations on surface treatment / is called the total allowance" [5].

The perception of an emphatic text is associated with the speaker's communicative intention, which brings together such parameters of the phrase as an external linguistic shell, internal content, pragmatic task and its functional purpose (for example, the impact and transfer of the author's "I". That is why a person trusts the speaker's intonation more than the direct meaning of the statement. Let us turn to examples: "The most expedient is the initial workpiece, which requires the lowest costs in the manufacture of a part, taking into account all technological processing operations and the required quality of the part" [5]. The content of this sentence can vary depending on the variation of the accent nuclei: emphatically emphasizing the phrase "initial blank", the speaker introduces the topic of the statement; the 
selection of the participial turnover characterizes this topic, and the predicate, expressed in a comparative degree, focuses on the intensity of the manifestation of signs.

It can be seen that, depending on the current speech situation or the intentions of the addressee of the utterance, the same phrase can be uttered with different content. Distinctive dominance in this case serves as an indicator of communicative significance. At the initial stage of teaching Russian as a foreign language, emphatic intonation, highlighting a contextual phrase reflecting the derivation of meanings is not specially taught, therefore foreigners have difficulty in semantic perception and development of the phrase, overcoming difficulties in an associative way: they perceive the phrase directly in the process of pronunciation. Self-orientation towards the restoration of word series "binds" the learner to specific lexemes, as a result of which the inertia of the words already spoken increases. On the other hand, the meaning complex is a product of the act of understanding, and not a program of speech actions. Associative processes by themselves cannot form an integral semantic perception of an utterance, therefore, the teacher should at least superficially familiarize students with the features of emphatic intonation by focusing on a conscious search for contextual meaning, actualization of lexical-semantic fields, simultaneous balanced action of associative and predicative factors of speech production, nonlinearity of verbal deployment "meaning - word", which creates a semantic hierarchy of the utterance.

The development of the ability to accurately determine the boundaries of an utterance can serve as a starting point in the formation of foreign students' skills for a comprehensive perception and understanding of the Russian context. Therefore, it is important to show them the range of accent intonation on the material of emphatic constructions (highlighted phrases) that are included in scientific syntaxemes. In the process of a detailed statement, it is important to teach foreign students the exact ratio of the options for the intonational design of a syntactic unit with its text load. This is what contributes to the effective perception of the meaning of the message by foreign students. In this regard, it is important to show a foreigner that during emphases, objectivity is often put forward in the first place (due to the high informativeness of nouns in postposition), and the transfer of the verb to the preposition blurs the meaning of the action, which gives the whole sentence the meaning of a statement of fact, "reflecting the communicative attitude speaking to emphasize the basic semantic components of the message" [7].

Due to the emphatically accented subject, the structural and semantic connections of the sentence change, therefore "the development of the content filling of the orally presented scientific text directly depends on the intonational accentuation of the phrase segment (emphase)" [8. However, in some contexts, the subject-rhema is emphasized additionally (if there is a comparison, opposition, emphasis, etc.) and can be highlighted with wordsactualizers: "The machines are located in the sequence of technological operations, / and the parts are processed in batches / on these machines. Only after completion / processing, the batch of blanks is delivered to the next machine, to a reserve site or intermediate warehouse" [5]. The particle "only" in the microtext presented above reflects the subjective in the objective, and at the same time, being interconnected with the communicative intention of the speaker and the illocutionary force of the utterance [7], It is also capable of performing a suggestive function: during the emphasis on a particle, "only" background information is transmitted about the exact sequence of actions in the manufacture of parts, and a violation of this sequence can lead to a discrepancy in the quality of products. The mechanism of speech influence in such syntaxemes is built according to a certain template: the supply of an informative component and the veiling of the suggested. As can be seen from the example, actualizing words have an amplifying, excretory or restrictive meaning and convey hidden additional meanings. The repetition of the word "machine" and emphasis on it serves as a well-known indicator of their communicative significance: the allocated segments not only most actively realize their possibilities of accentuation (the proof of which is their frequent 
use), but also most fully reflect the semantic specifics of the lexical-semantic group, are its most active influencing element. The use of the demonstrative pronoun "these" refers the addressee of the utterance to the contextual content, which does not need a broader clarification and is given to the recipient for conjecture [4], which allows us to say that demonstrative pronouns as grammatical markers of emphase carry a slightly different semantic and expressive load. rather than nouns.

If the sentence is a complex structure with synonymous unions, then it can be seen that the pragmatic orientation of the content is especially clearly traced in them. It is the synonymy of unions that allows not only to avoid repetitions, but also to reveal the nuances of the meanings of the subordinate clause: "The most productive is the continuous-flow form of organization, when the workpieces move through the workplaces in accordance with the technological process, and the piece processing time in all operations is coordinated with the cycle of the production line". [5]. In this example, a synonymy of union lexemes "if", "at which" and "when" is traced in the definitive clause. A materially or non-materially expressed union link brings its meaning into the defined distribution (add time and condition to its shade) and conveys a personally marked attitude towards the entire phrase.

\section{Discussion}

All the properties and functions of emphasis described above as a special type of intonation at different times aroused the interest of philosophers, psychologists and linguistic scientists, who argued that the nature of any language is suggestive, since its units, in addition to direct nomination, also convey subjective implications [9]. Such a scientific understanding of emphase is forced to revise the methodological techniques of teaching any branch of science, and especially the methods of Russian as a foreign language. The ways of solving this problem were outlined in the works [10-13] and others when creating a communicatively oriented grammar of an utterance, as well as in the field of intonology when studying the patterns of highlighting a particular lexeme in a speech stream in order to actualize a certain content plan and describe the conditions of text loads of intonation accentuation [14-15]. Based on the results of research in the field of super-segmental structure that emphasis, semantically expands the phrase and changes the structure of the sentence, the authors of this article attempted to give an in-depth structural and semantic analysis of accent words in a scientific phrase based on lecture texts on mechanical engineering. The results of the performed work allowed the teachers of the Russian language to outline possible ways of using them in the educational process in terms of developing the abilities of foreign students to determine the communicative intentions of the addressee of the statement.

\section{Conclusion}

The results of the obtained studies allow us to say that emphasis can act as an independent level of the linguistic structure, which has its own formal and semantic units. And if intonation performs the function of organizing and dividing the speech stream, then emphatic intonation, conveying hidden additional meanings and focusing on pragmatics, also implements a suggestive function: the speaker, changing voice tones, highlights important content-wise lexemes and introduces a "I" position into relation to what has been said.

As applied to the methodology of teaching Russian as a foreign language, knowledge of the described features of emphatic utterances will allow language teachers to choose such a form of presentation of linguistic material, which in the future will help to eliminate erroneous intonation in the perception of lectures in a specialty, since the possibility of teaching in a foreign language, we believe, in many ways depends on the level of mastering 
the principles of highlighting the direct and veiled content of the text of the scientific style of speech. Therefore, the correct understanding by foreign students of emphatic phrases will help them already at the stage of pre-university education to master the basic lexical and syntactic structures of the language of the future specialty [10], to identify the speaker's communicative strategy and, on this basis, to formulate correctly their own oral statement in accordance with the communicative task.

\section{References}

1. B. Strickland, M. Fisher, F. Keil, et al., Cognition, 133 (1), 249-261 (2014) URL: www.sciencedirect.com/science/article/pii/S0010027714001103

2. L. F. Otano, A.O. Sanchez Avila, J.C. Villamar, et al., Electronic journal. Buenos Aires, 230 (2017) URL: https://www.efdeportes.com/efd230/the-intonation-in-the-oralexpression.htm

3. H. Farzaneh, M. Kaiser, U. Lindemann, Creative processes in groups - relating communication, cognitive processes, and solution ideas, The 2nd International Conference on Design Creativity (ICDC2012) Glasgow, UK (2012)

4. C. R. Scherrer, Journal of Women and Minorities in Science and Engineering, 19(1), 37-45 (2013)

5. V. Chekmarev, Agroengineering, 58 (2018)

6. N.Chater, S.M. McCauley, M.H. Christiansen, Journal of Memory and Language, 89, 244-254 (2016) URL: www.sciencedirect.com/science/article/pii/S0749596X15001412 (Last accessed 20.01.2021)

7. O. Nikolenko, L. Babakova, B. Morenko, International education and cooperation, MADI, Moscow, 104-109 (2020)

8. Z. Huang, S.Feng, W. Su, et al., ERNIE at SemEval-2020. Task 10: Learning word emphasis selection by pre-trained language model. In Proceedings of the 14th International Workshop on Semantic Evaluation (2020)

9. Y. Mass, S. Shechtman, M. Mordechay, et al., In Interspeech, 2868-2872 (2018)

10. O. Nikolenko, A. Belozerova, N. Sumina, et al., Parcelled phrases in the aspect of business communication, Breakthrough Technologies and Communications in Industry. International Scientific Practical Conference. Volgograd, Russian Federation, 673 (2018) DOI.org/10.1051/shsconf/20196900081

11. G.Ferguson, C. Perez-Llantada, R. Pio, A Study of Attitudes World Englishes. 30, 4159 (2011) DOI: 10.1111/j.1467-971X.2010.01656.x

12. H. Clark, Cambridge handbook of psycholinguistics. Cambridge: Cambridge University Press, 541-557 (2012)

13. I.L. Funtova, The Institute of Linguistics and Intercultural Communication attached to Moscow State Regional University, Russian linguistic bulletin, 1(17), 17-20 (2019) DOI: https://doi.org/10.18454/RULB.2019.17.1.4

14. T. Johnen, Intercultural competence. Concepts, challenges, evaluations, Bern, 341-357 (2011) DOI: https://doi.org/10.1051/e3sconf/202021018030

15. O. Nikolenko, O. Zakharchuk, L. Babakova, et al., The 'I' of the author and its persuasive function (as exemplified by the complex sentence with homogeneously collateral sub clauses). The International Scientific and Practical Conference Current Issues of Linguistics and Didactics: The Interdisciplinary Approach in Humanities and Social Sciences, SHS Web of Conferences, 69, 00081 (2019) 